\title{
Milestone M3FT-15OR0202268: Delivery of completed irradiation vehicles and the quality assurance document to the High Flux Isotope Reactor for irradiation
}

\author{
Christian Petrie ${ }^{1}$, Joel McDuffee ${ }^{1}$, Yutai Katoh ${ }^{1}$, Kurt Terrani $^{1}$ \\ ${ }^{1}$ Oak Ridge National Laboratory, Oak Ridge, TN, 37831-6051
}

\section{Introduction}

This report details the initial fabrication and delivery of two Fuel Cycle Research and Development (FCRD) irradiation capsules (ATFSC01 and ATFSC02), with associated quality assurance documentation, to the High Flux Isotope Reactor (HFIR). The capsules and documentation were delivered by September 30, 2015, thus meeting the deadline for milestone M3FT-15OR0202268. These irradiation experiments are testing silicon carbide composite tubes in order to obtain experimental validation of thermo-mechanical models of stress states in SiC cladding irradiated under a prototypic high heat flux. This document contains a copy of the completed capsule fabrication request sheets, which detail all constituent components, pertinent drawings, etc., along with a detailed summary of the capsule assembly process performed by the Thermal Hydraulics and Irradiation Engineering Group (THIEG) in the Reactor and Nuclear Systems Division (RNSD). A complete fabrication package record is maintained by the THIEG and is available upon request.

\section{Experimental Design}

The capsule design uses an embossed aluminum foil to transfer heat from the cladding and sleeve (see Figure 1) to the capsule housing. The foil compresses as the cladding swells under irradiation and keeps the clad surface temperature approximately constant throughout the irradiation. Heat transfer through the embossed foil has been validated experimentally (see Figure 2). This design allows the $\mathrm{SiC}$ tubes can be irradiated under a representative light water reactor temperature $\left(300-350{ }^{\circ} \mathrm{C}\right.$ outer surface temperature) and heat flux $\left(0.5-1.0 \mathrm{MW} / \mathrm{m}^{2}\right)$. The molybdenum heaters provide the heat generation required to reach the desired heat flux. Titanium centering thimbles keep both the $\mathrm{SiC}$ tube specimens and the molybdenum heaters centered within the capsule housing. Figure 1 shows a stack up of two $16 \mathrm{~mm}$ length specimens, one $12 \mathrm{~mm}$ length specimen, and one $4 \mathrm{~mm}$ length specimen. Alternatively, a stack up of three $16 \mathrm{~mm}$ length specimens can be used. This alternate stacking arrangement with three $16 \mathrm{~mm}$ length specimens was used for capsules ATFSC01 and ATFSC02, which were assembled and delivered to the HFIR for insertion during cycle 462 (October 2015). 


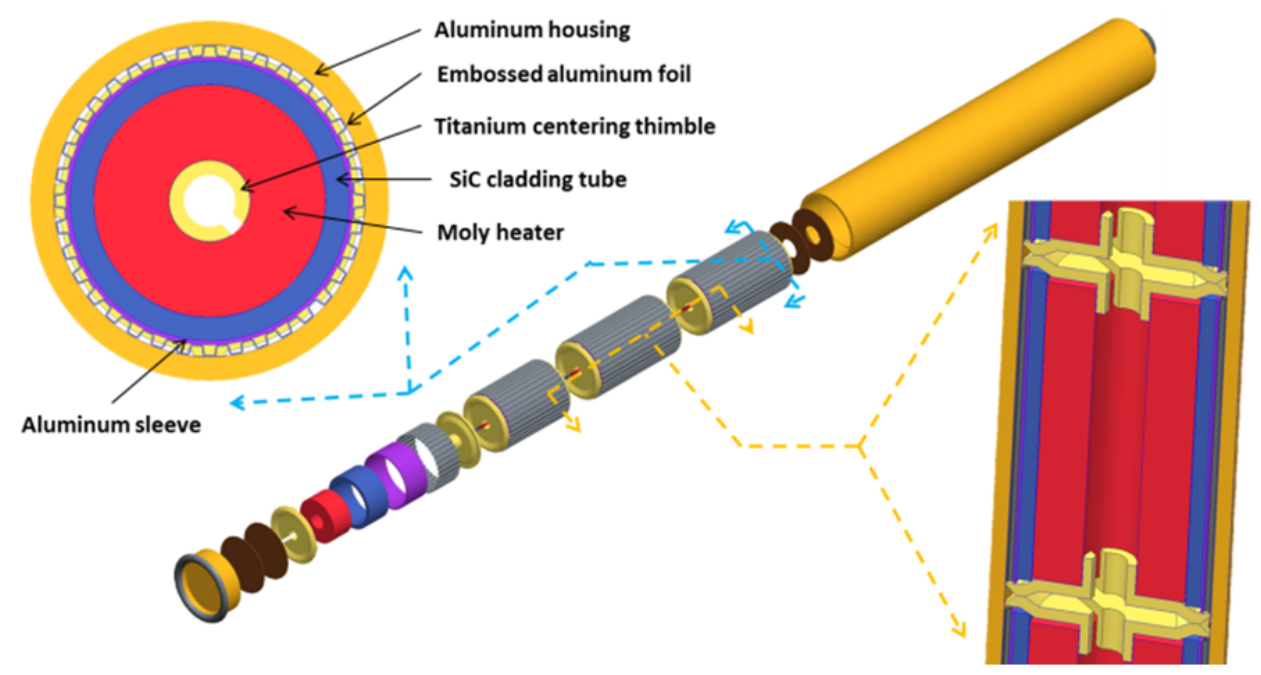

Figure 1. Schematic overview of experimental design
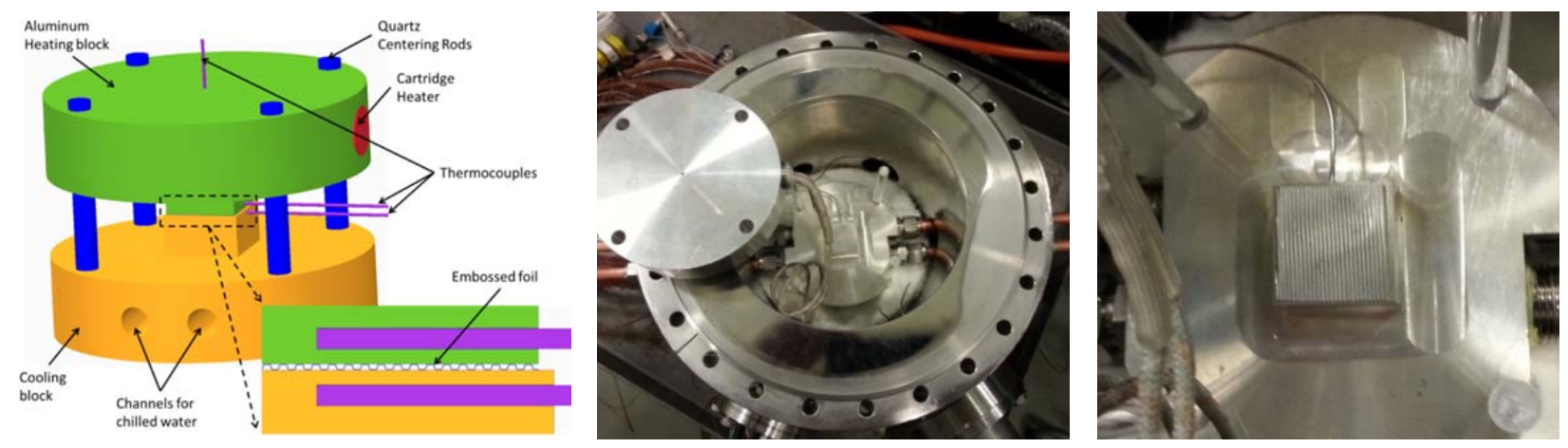

Figure 2. Validation experiment schematic (left), and pictures of the experimental rig (center) and foil loaded inside the rig (right).

\section{Component Fabrication}

Silicon carbide composite tube specimens were manufactured by General Atomic (GA). Composite tube specimens GA-TGI-1 and GA-TGI-4 were loaded into capsules ATFSC01 and ATFSC02, respectively. Pictures of these specimens are provided in Figure 3. In addition to the composite tube specimens, two CVD SiC tubes (monoliths) were loaded into each capsule to serve as a reference for comparison between the composites and the monoliths. The embossed aluminum foils were fabricated using a custom foil fabrication system (see Figure 4) that allows the foils to be rolled through mating gears without tearing the foil. 

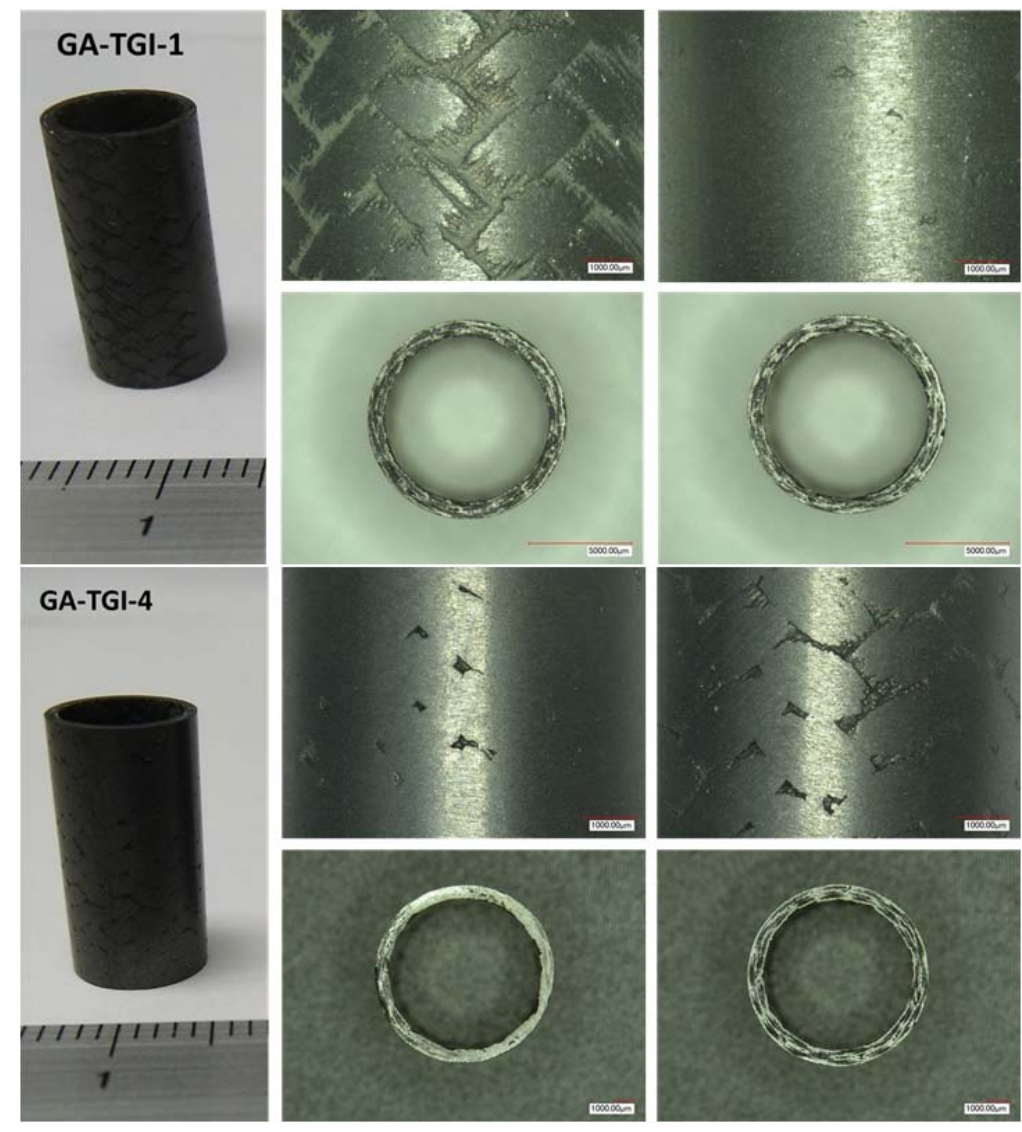

Figure 3. Pictures of SiC composite tube specimens GA-TGI-1 (top) and GA-TGI-4 (bottom)

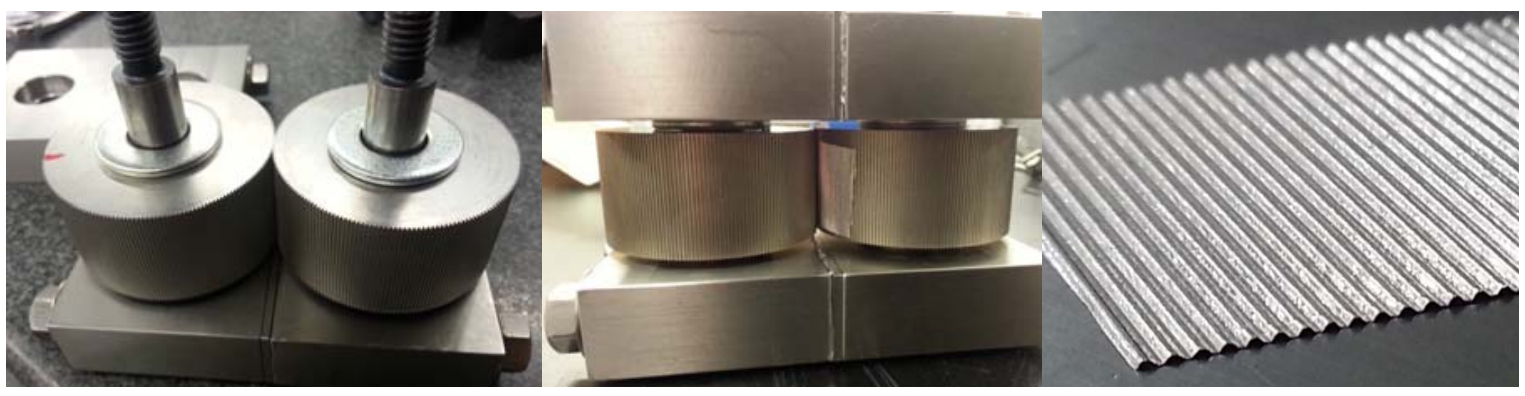

Figure 4. Pictures of the foil fabrication system

\section{Capsule Assembly}

The centering thimbles were pressed into the molybdenum heaters and the $\mathrm{SiC}$ tubes were inserted around the heaters. The sleeve was rolled around gage pins of the appropriate diameter and then wrapped tightly around the SiC tubes. The embossed foils were then wrapped around the sleeve to form the subassemblies (i.e. two centering thimbles, a heater, tube, sleeve, and foil). The sub- assemblies were then pressed into the housing. The foils were sized so that they must be compressed during insertion to ensure that there is good contact at the tube/sleeve, sleeve/foil, and foil/housing interfaces. Figure 5 shows pictures taken during the assembly process including the sub-assemblies and the fully assembled rabbit housings. 

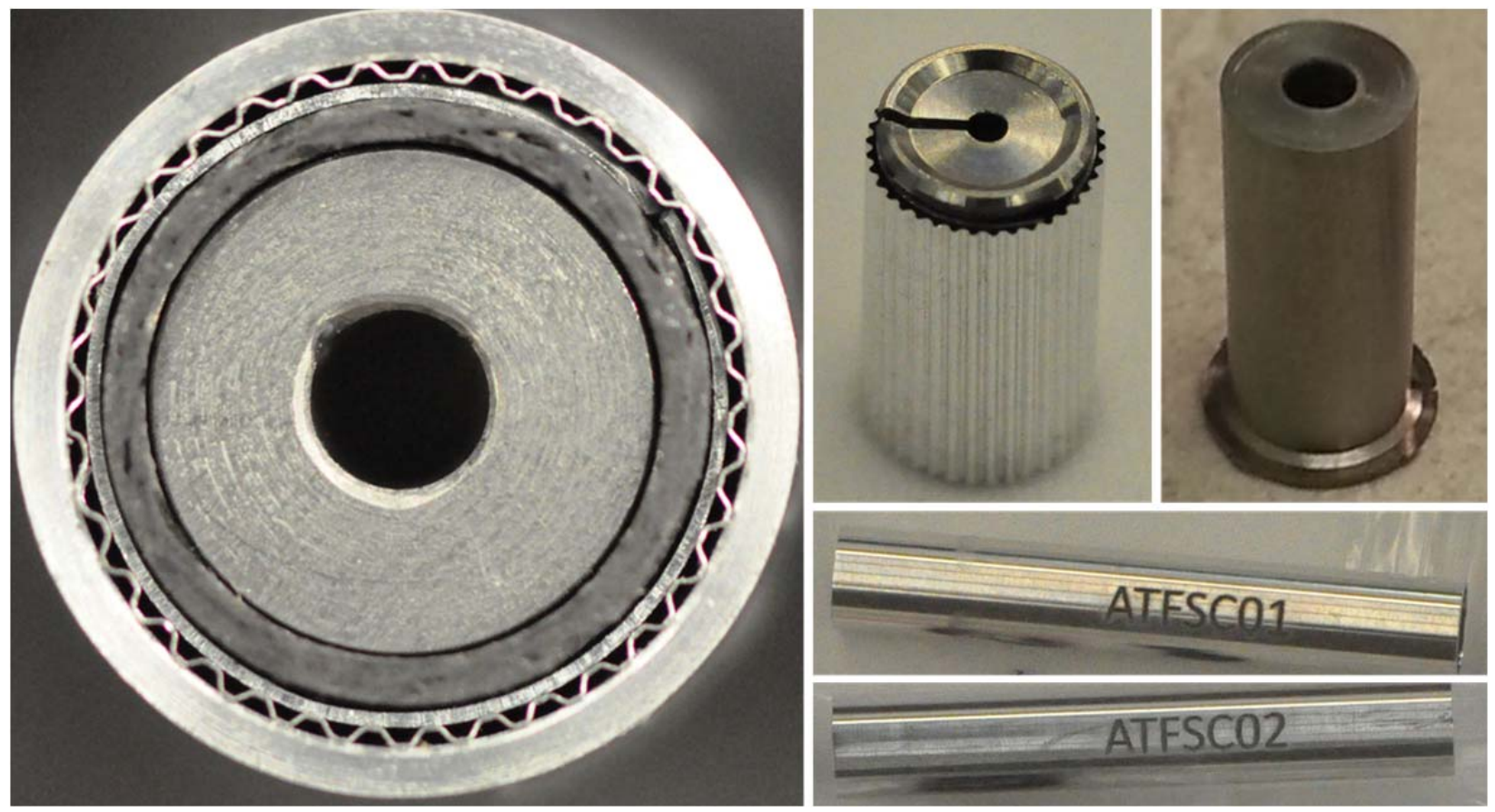

Figure 5. Pictures of sub-assembly in capsule housing (left), building of sub-assemblies (top right), and fully assembled capsules (bottom right)

\section{Final Capsule Welding and Testing}

Upon successful assembly of the capsules, the end caps were electron beam welded to the housings. Preliminary non-destructive examination (NDE) was performed on the end cap trepan welds to ensure that the weld joints were hermetically sealed. A final sealing weld was then made for each capsule, providing an inert helium internal atmosphere for all capsules. A formal helium leak rate test and external hydrostatic compression test were performed on the capsules to ensure they were properly sealed. THIEG engineering staff used the final loading and assembly data to perform the necessary evaluations required to ensure that each capsule is bounded by existing HFIR safety basis calculations and meets the requirements of the ORNL Research Reactor Division's Experiment Authorization Bases Document EABD-HFIR-2009-004 Rev. 11. Upon completion of the THIEG review, the capsules were delivered to the HFIR for final quality assurance review and insertion for irradiation. 
ORNL/LTR-2015/569

Attachments - Fabrication Request Sheets 
ORNL/LTR-2015/569

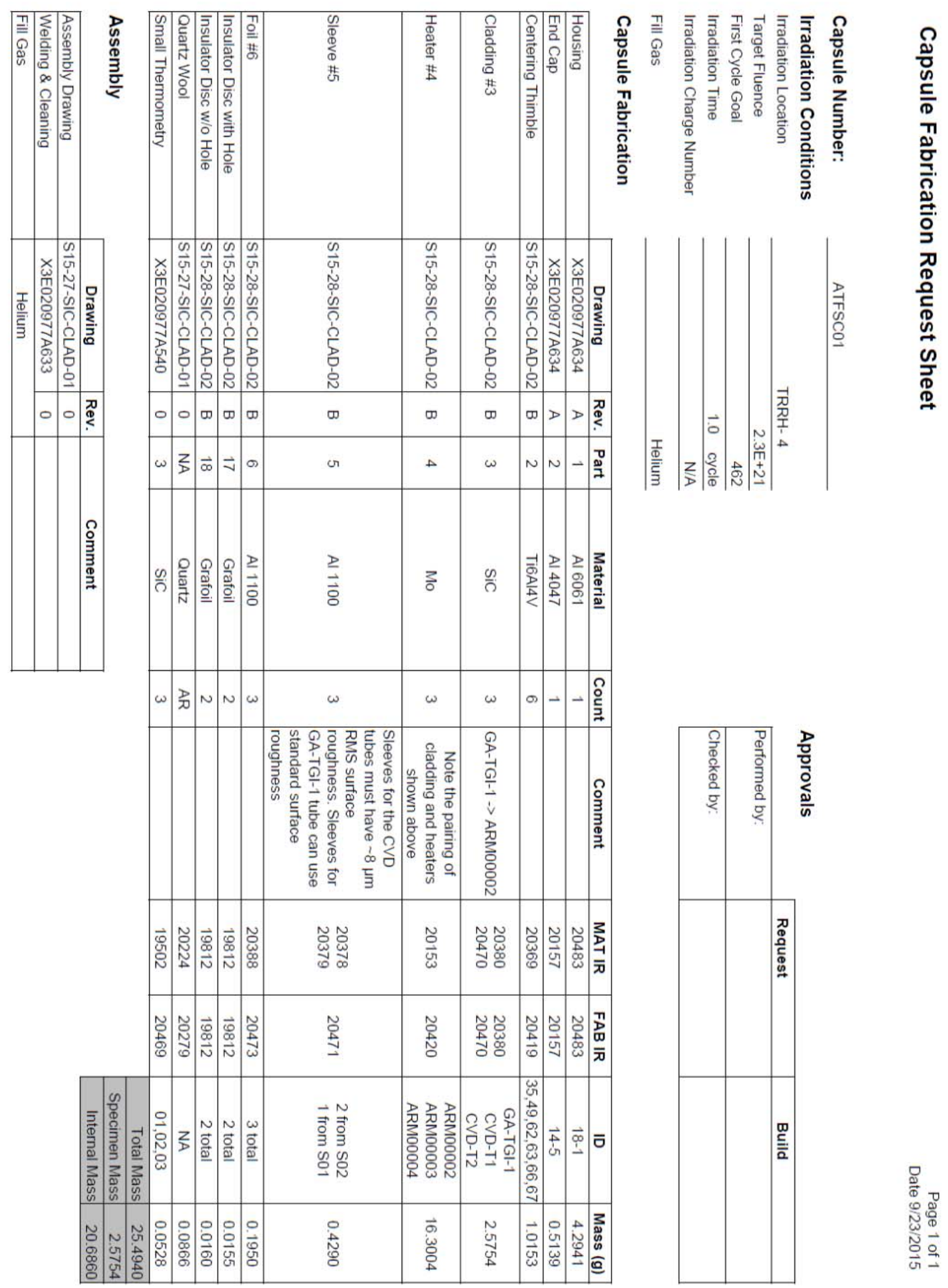


ORNL/LTR-2015/569

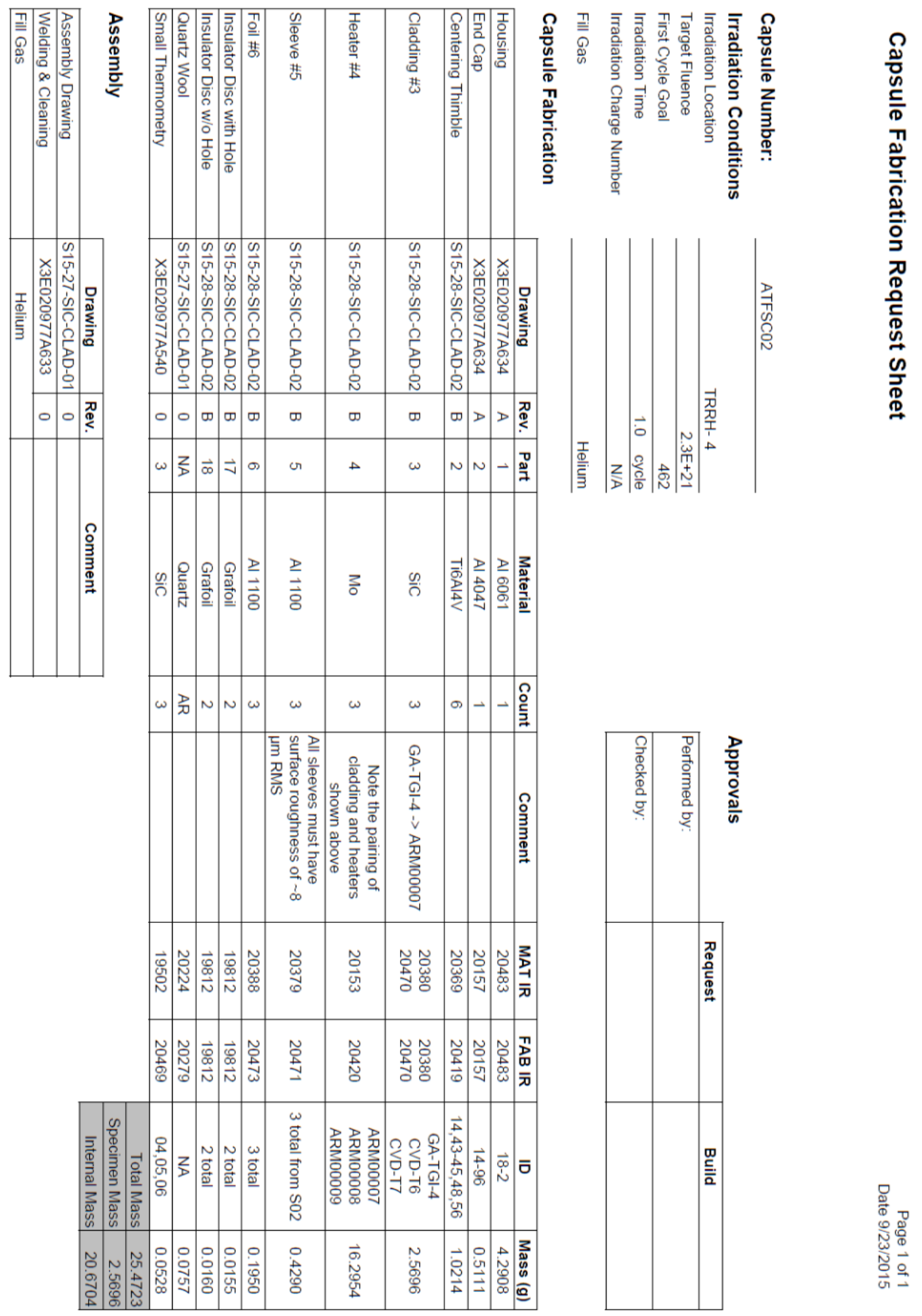

